\title{
New Method for Determinations of Association and Dissociation Rate Constants of Reversible Bimolecular Reactions by Isothermal Titration Calorimeters
}

Tsuyoshi Egawa, Antonio Tsuneshige, Makoto Suematsu and Takashi Yonetani

Department of Biochemistry and Biophysics and the Johnson Research Foundation, University of Pennsylvania Medical Center, Philadelphia, PA 19104-6059 and Department of Biochemistry and Integrated Medical Biology, School of Medicine, Keio University, Shinanomachi, Shinjuku-ku, Tokyo 160-8582.

\section{Supporting Information}

\section{Contents}

Supporting Figure S1

Appendix

Supporting Discussion

References 

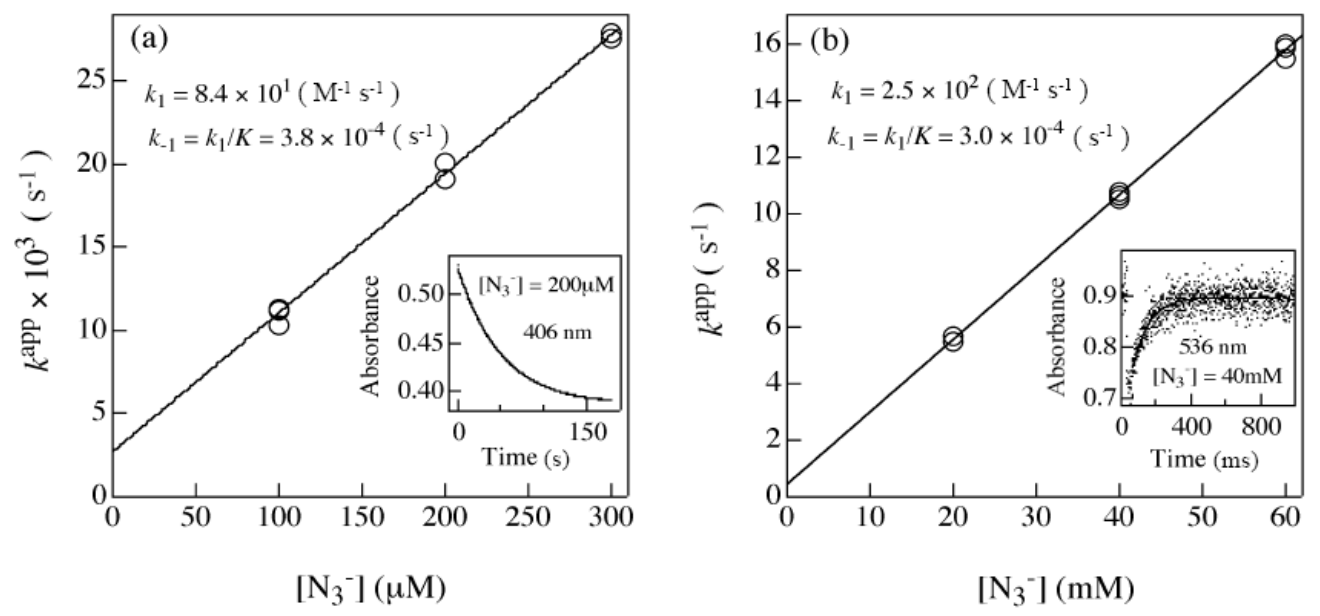

Figure S1. Spectrophotometric determinations of the association and dissociation rate constants between $\mathrm{N}_{3}{ }^{-}$and the ferric hemes of $\alpha^{3+} / \beta^{2+}-\mathrm{CO}$ (a) or $\beta^{3+} / \alpha^{2+}-C O(b)$ hemoglobins under pseudo first-order conditions. Apparent rate constants of the binding with $\mathrm{N}_{3}{ }^{-}$were obtained for $2.3 \mu \mathrm{M}$ of $\alpha^{3+} / \beta^{2+}-\mathrm{CO} \mathrm{Hb}$ by using ordinary spectrophotometer (Hewlett Packard, 8452A) and for $160 \mu \mathrm{M}$ of $\beta^{3+} / \alpha^{2+}-\mathrm{CO}$ $\mathrm{Hb}$ by a rapid-scan spectrophotometer (Olis RSM 1000) equipped with a stopped-flow apparatus (UNISOKU). Extinction coefficient values employed for determining heme concentrations of carbonmonoxy $\mathrm{Hb}$ were $13.4 \mathrm{~cm}^{-1} \mathrm{mM}^{-1}(540 \mathrm{~nm}){ }^{1} \quad$ The association rate constants $k_{1}$ were obtained from the slopes of the plots, while the dissociation rate constants $k_{-1}$ were obtained according to the equation $K=k_{1} / k_{-1}$. Upon the binding with $\mathrm{N}_{3}{ }^{-}$, the ferric hemes undergo optical absorption changes in the Soret (380-430 nm) and visible (500-700 nm) region. The insets show examples of observed absorption changes (broken curves) at $406 \mathrm{~nm}$ (in (a), for $\alpha^{3+} / \beta^{2+}-\mathrm{CO}$ at $\left[\mathrm{N}_{3}{ }^{-}\right.$] $=200 \mu \mathrm{M})$ and $536 \mathrm{~nm}$ (in (b), for $\beta^{3+} / \alpha^{2+}-\mathrm{CO}$ at $\left[\mathrm{N}_{3}{ }^{-}\right]=40 \mathrm{mM}$ ) together with single exponential fitting curves (solid curves). 


\section{APPENDIX}

(I) Our ITC instrument is designed in a way that each injection of ligand molecule (L) to the solution of sample molecule (M) acts to drive liquid out of the working volume $\left(\mathrm{V}_{0}\right)$, which is sensed calorimetrically. Thus the total concentration (the sum of the free and bound forms) of $\mathrm{M}$ after $n^{\text {th }}$ injection $\left(\mathrm{c}^{\mathrm{T}} \mathrm{M}(n)\right)$ and that of $\mathrm{L}$ $\left(c^{\mathrm{T}} \mathrm{L}(n)\right)$ depend on the injection volume $(\Delta \mathrm{V})$ etc., and they are given by

$$
\mathrm{c}_{\mathrm{M}}^{\mathrm{T}}(n)=\mathrm{c}_{\mathrm{M}}^{\text {Cell }} \frac{2 \mathrm{~V}_{0}-n \Delta \mathrm{V}}{2 \mathrm{~V}_{0}+n \Delta \mathrm{V}} \quad \mathrm{c}_{\mathrm{L}}^{\mathrm{T}}(n)=\mathrm{c}_{\mathrm{L}}^{\text {Syringe }} \frac{n \Delta \mathrm{V}\left(2 \mathrm{~V}_{0}-n \Delta \mathrm{V}\right)}{2\left(\mathrm{~V}_{0}\right)^{2}}
$$

where $\mathrm{c}^{\mathrm{Cell}} \mathrm{M}$ is the concentration of $\mathrm{M}$ in the ITC cell before the first injection, while $\mathrm{c}^{\text {Syringe }} \mathrm{L}$ is that of $\mathrm{L}$ stored in the injection syringe. ${ }^{2}$

Using $\mathrm{c}^{\mathrm{T}} \mathrm{M}(n), \mathrm{c}^{\mathrm{T}} \mathrm{L}(n)$ and the association constant $(K)$ between $\mathrm{M}$ and $\mathrm{L}$, the concentration of the complex ML after $n^{\text {th }}$ injection is given by, ${ }^{2}$

$$
\mathrm{c}_{\mathrm{ML}}(n)=\frac{1}{2}\left\{\mathrm{c}_{\mathrm{M}}^{\mathrm{T}}(n)+\mathrm{c}_{\mathrm{L}}^{\mathrm{T}}(n)+\frac{1}{K}-\sqrt{\left(\mathrm{c}_{\mathrm{M}}^{\mathrm{T}}(n)+\mathrm{c}_{\mathrm{L}}^{\mathrm{T}}(n)+\frac{1}{K}\right)^{2}-4 \mathrm{c}_{\mathrm{M}}^{\mathrm{T}}(n) \mathrm{c}_{\mathrm{L}}^{\mathrm{T}}(n)}\right\}
$$

and the concentrations of free molecules are given as follows.

$$
\mathrm{c}_{\mathrm{M}}^{\mathrm{f}}(n)=\mathrm{c}_{\mathrm{M}}^{\mathrm{T}}(n)-\mathrm{c}_{\mathrm{ML}}(n) \quad \mathrm{c}_{\mathrm{L}}^{\mathrm{f}}(n)=\mathrm{c}_{\mathrm{L}}^{\mathrm{T}}(n)-\mathrm{c}_{\mathrm{ML}}(n)
$$

(II) When an experimentally observed time profile $f(t)$ is a convolution between a time dependent event $g(t)$ and an instrument function $h(t)$, then $f(t)$ is given as follows.

$$
f(t)=\int_{0}^{t} h(\tau) g(t-\tau) d \tau
$$

If $g(t)$ in the above equation is a single exponential function with an amplitude factor A and a time constant $\mathrm{B}$, then,

$$
\begin{aligned}
f(t) & =\int_{0}^{t} h(\tau) \mathrm{A} e^{-\mathrm{B}(t-\tau)} d \tau \\
& =\mathrm{A} e^{-\mathrm{B} t} \int_{0}^{t} h(\tau) e^{\mathrm{B} \tau} d \tau \\
& =\frac{\mathrm{A}}{\mathrm{B}} e^{-\mathrm{B} t}\left\{\left[h(\tau) e^{\mathrm{B} \tau}\right]_{0}^{t}-\int_{0}^{t} \frac{d[h(\tau)]}{d \tau} e^{\mathrm{B} \tau} d \tau\right\} .
\end{aligned}
$$


Since $h(t)$ is induced as a response to the time dependent event $g(t), h(t)=0$ at $t=0$. Thus the above equation can be rearranged as follows.

$$
f(t)=\frac{\mathrm{A}}{\mathrm{B}} e^{-\mathrm{B} t}\left\{h(t) e^{\mathrm{B} t}-\int_{0}^{t} \frac{d[h(\tau)]}{d \tau} e^{\mathrm{B} \tau} d \tau\right\}
$$

Differentiating the above equation gives followings.

$$
\begin{aligned}
\frac{d[f(t)]}{d t} & =-\mathrm{B} f(t)+\frac{\mathrm{A}}{\mathrm{B}} e^{-\mathrm{B} t}\left\{\frac{d[h(t)]}{d t} e^{\mathrm{B} t}+h(t) \mathrm{B} e^{\mathrm{B} t}-\frac{d}{d t} \int_{0}^{t} \frac{d[h(\tau)]}{d \tau} e^{\mathrm{B} \tau} d \tau\right\} \\
& =-\mathrm{B} f(t)+\frac{\mathrm{A}}{\mathrm{B}} e^{-\mathrm{B} t}\left\{\frac{d[h(t)]}{d t} e^{\mathrm{B} t}+h(t) \mathrm{B} e^{\mathrm{B} t}-\frac{d[h(t)]}{d t} e^{\mathrm{B} t}\right\} \\
& =-\mathrm{B} f(t)+\mathrm{A} h(t)
\end{aligned}
$$

Accordingly,

$$
h(t)=\frac{1}{\mathrm{~A}}\left\{\frac{d[f(t)]}{d t}+\mathrm{B} f(t)\right\}
$$

On the other hand, the instrument functions are determined as a normalized function. Therefore,

$$
\int_{0}^{\infty} h(t) d t=\int_{0}^{\infty} \frac{1}{\mathrm{~A}}\left\{\frac{d[f(t)]}{d t}+\mathrm{B} f(t)\right\} d t=1
$$

and then,

$$
\int_{0}^{\infty}\left\{\frac{d[f(t)]}{d t}+\mathrm{B} f(t)\right\} d t=[f(t)]_{0}^{\infty}+\mathrm{B} \int_{0}^{\infty} f(t) d t=\mathrm{A} .
$$

If $f(t)$ is an ITC heat flow signal and it loses the intensity within finite term, $f(t)=0$ at $t$ $=\infty$, and also $f(t)=0$ at $t=0$. Then the first term of the middle part of the above equation can be removed, and the amplitude factor $\mathrm{A}$ is given as follows.

$$
\mathrm{A}=\mathrm{B} \int_{0}^{\infty} f(t) d t
$$

Substituting Eq. (A2) into Eq. (A1) gives 


$$
h(t)=\phi^{\prime}(t) \frac{1}{\mathrm{~B}}+\phi(t)
$$

where,

$$
\phi(t) \equiv \frac{1}{\int_{0}^{\infty} f(t) d t} f(t)
$$

and

$$
\phi^{\prime}(t) \equiv \frac{1}{\int_{0}^{\infty} f(t) d t} \frac{d[f(t)]}{d t}
$$

Rearranging terms of Eq. (A3) gives the following equation.

$$
\phi^{\prime}(t)=\mathrm{B}\{h(t)-\phi(t)\}
$$




\section{Supporting Discussion}

Since the present ITC experiments took a bit long time (more than 10 hour for single experiment), a small level of autoxidation ${ }^{3}$ of ether $\alpha^{2+}-\mathrm{CO}$ or $\beta^{2+}-\mathrm{CO}$ hemes took place in each titration experiment. Small differences in $k_{1}$ between the present ITC method $\left(\alpha^{3+} / \beta^{2+}-\mathrm{CO}, 8.8 \times 10^{1} ; \beta^{3+} / \alpha^{2+}-\mathrm{CO}, 2.1 \times 10^{2} \mathrm{M}^{-1} \mathrm{~s}^{-1}\right)$ and the spectroscopic experiments $\left(\alpha^{3+} / \beta^{2+}-\mathrm{CO}, 8.4 \times 10^{1} ; \beta^{3+} / \alpha^{2+}-\mathrm{CO}, 2.5 \times 10^{2} \mathrm{M}^{-1} \mathrm{~s}^{-1}\right)$ could be attributed, in part, to the autoxidation. When $\beta^{2+}-\mathrm{CO}$ heme of the $\alpha^{3+} / \beta^{2+}$-CO sample was autoxidized to $\beta^{3+}$, then $k_{1}$ would involve contribution of binding at $\beta^{3+}$ and apparently increases, while when $\alpha^{2+}$ - CO heme of the $\beta^{3+} / \alpha^{2+}-\mathrm{CO}$ was autoxidized to $\alpha^{3+}, k_{1}$ would decrease. 
References

(1) Antonini, E.; Brunori, M. In Hemoglobin and Myoglobin in Their Reactions with Ligands; Neuberger, A., Tatum, E. L., Eds; North-Holland Publishing Co.: Amsterdam, 1971; Vol 21, Chapter 2.1

(2) ITC Data Analysis in Origin $®$ - Tutorial Guide, MicroCal, LLC.: Northampton, MA, 2004; Version 7.0

(3) Antonini, E.; Brunori, M. In Hemoglobin and Myoglobin in Their Reactions with Ligands; Neuberger, A., Tatum, E. L., Eds; North-Holland Publishing Co.: Amsterdam, 1971; Vol 21, Chapter 2.2.3 